\title{
UMA RESPOSTA SÓLIDA A UM REGIME AGROALIMENTAR EM CRISE O fenômeno GAS na Itália
}

\section{Flávio Sacco dos Anjos}

Universidade Federal de Pelotas (UFPel), Pelotas - RS, Brasil. E-mail: saccodosanjos@gmail.com

\section{Nádia Velleda Caldas}

Universidade Federal de Pelotas (UFPel), Pelotas - RS, Brasil. E-mail: velleda.nadia@gmail.com

DOI: $10.17666 / 329513 / 2017$

\section{Introdução}

Até meados do século XX, o tecido social e produtivo que congregava produtores, transformadores, distribuidores e consumidores em torno do que comíamos e bebíamos ocupava um lugar secundário nas preocupaçóes sociais. Esse fato traduzia a progressiva redução da parte da renda destinada pelas famílias à aquisição de produtos alimentícios como resultado do crescimento na oferta de produtos agrícolas para o conjunto da populaçáo. Nesse contexto, o rosário de escândalos agroalimentares (crise das dioxinas, doença da vaca louca, gripe aviária e suína, febre aftosa, transgênicos etc.) que eclode na cena cotidiana representa tão-somente a ponta de um grande iceberg que afeta o mundo da alimentação em toda a sua complexidade.

Artigo recebido em 10/06/2016

Aprovado em 25/05/2017
Dentro das grandes cadeias que configuram os sistemas agroalimentares à escala planetária, a crescente desvinculação entre produto agrário e produto alimentício (Langreo, 1988) delimita uma transformação copernicana na estrutura de poder que comanda a esfera da produção, transformação, abastecimento e consumo alimentar. Do ponto de vista social, crescem as preocupaçóes sobre a origem e natureza dos alimentos consumidos, assumindo a forma de uma "caixa negra" (Contreras, 2002) devido ao alto grau de invisibilidade, incerteza e desconfiança a que estamos submetidos.

Em maior ou menor medida, tais aspectos e circunstâncias contribuíram para a "proeminência espetacular" (Scott, 2006) experimentada, nas duas últimas décadas, tanto pela sociologia do consumo como pela sociologia da alimentação (Díaz Méndez e Espejo, 2014). Nesse sentido, se até então o consumo assumia conotaçóes negativas como um ato que significava "destruir, desperdiçar, exaurir" 
(Scott, 2006, p. 50), cresce a convicção de que as ações dos consumidores são cruciais enquanto mecanismos de construção de identidades sociais e de estilos de vida (Bourdieu, 1979), assim como a expressão insofismável de exercício da cidadania (Portilho, 2005). Consumir e alimentar-se é cada vez mais visto como um ato produtor de significados, que transcende a mera satisfação de necessidades imediatas.

Eis algumas das chaves que nos permitem compreender a diversidade de sistemas de abastecimento alimentar que colorem a paisagem de médias e grandes cidades do mundo ocidental. Até bem pouco tempo atrás, as tradicionais feiras livres, os mercados públicos e as grandes superfícies de varejo eram as formas privilegiadas de acesso ao alimento. Não obstante, modalidades inovadoras ganham relevo, a exemplo da venda direta de hortifrutigranjeiros, cuja ênfase recai, entre outros aspectos, no triplo esforço de reduzir as distâncias materiais e simbólicas que separam produtores e consumidores, eliminar assimetrias de informação e construir uma relação mais justa e equilibrada entre a órbita do consumo e a da produção.

Experiências como essas se inserem no escopo do que a literatura internacional denomina alternative food networks (redes agroalimentares alternativas), incluindo aquelas que exortam a forma ecológica el ou orgânica ${ }^{1}$ de produção agropecuária. Resumidamente são assim referidas as formas de produção e aprovisionamento de comida que divergem frontalmente da lógica que impera atualmente no sistema agroalimentar em nível mundial, o qual é caracterizado, entre outros aspectos, pela intensificação da agricultura, padronização dos alimentos e por processos que se desenvolvem através de cadeias longas, governadas por grandes corporaçóes e complexos agroindustriais que operam à escala planetária.

O foco deste artigo é analisar a mais importante experiência de rede agroalimentar alternativa existente na Itália - Gruppi di Acquisto Solidale (GAS) - com base em investigaçáo realizada naquele país durante o ano de 2015. Nossa atenção está centrada não somente no exame dos fatores que ocasionaram o seu surgimento, mas nos desafios que se apresentam na atualidade, por conta de sua peculiar lógica de funcionamento. Nessa aproximação, fizemos uso de diversos instrumentos de pesquisa, incluindo visitas técnicas aos produtores e aos locais onde esses grupos funcionam, entrevistas com diversos atores (consumidores, agricultores, técnicos etc.), consulta a materiais de divulgação impressa e digital, bem como a diversos filmes documentários que narram as singularidades dos GAS em todo o território italiano.

Para tal análise, o artigo foi subdividido em três seçóes. Na primeira delas, apresentamos os traços gerais que identificam as redes agroalimentares alternativas (doravante $\mathrm{AFN}^{2}$ ), assim como algumas das mais importantes contradiçôes associadas a esse conceito. A segunda seção aborda a dimensão crítica e política do consumo a partir dos aportes teóricos mais relevantes. E, na terceira seção, nossa mirada se orienta em direção às características dos GAS, desnudando os fatores e circunstâncias que acarretaram o seu surgimento e alguns dos desafios atuais dessa experiência. Abordamos também a sua peculiar lógica de funcionamento a partir do ponto de vista dos sujeitos implicados, fazendo uso das impressóes colhidas durante o trabalho de campo.

\section{Redes agroalimentares alternativas}

No auge dos anos de 1970, a ideia de uma agricultura alternativa se apresentava como antagônica ao padrão imposto pelas tecnologias da revolução verde. Com efeito, o termo "alternativo" traduzia a necessidade de contrapor-se às formas intensivas de produção, totalmente tributárias do uso de mecanização pesada, combustíveis fósseis, adubos químicos de alta solubilidade, agrotóxicos e melhoramento genético de cultivos e criações. Boa parte das energias dispendidas nos estudos rurais postulava a necessidade de superação do modelo produtivista de agricultura e de uma transição para um novo modelo de desenvolvimento rural (Cassol e Schneider, 2015, p. 149).

Todavia, a noção de AFN amplia o escopo da alternatividade ao transcender o âmbito da produção agropecuária stricto sensu. Estamos falando agora de estratégias de enfrentamento ao mainstream da distribuiçáo e do consumo de alimentos que vêm sendo edificadas no mundo ocidental, desde meados dos anos de 1980, em meio à ascensão dos 
“impérios agroalimentares" (Ploeg, 2008), os quais são regidos pela padronização dos produtos, pela lógica dos ganhos em escala e pelo domínio centralizado dos processos de produção, transformação, circulação, distribuição e consumo de alimentos.

Mas a última década foi pródiga em termos do número de estudos relacionados com as novas formas de produção e aprovisionamento de comida nos quatro cantos do planeta. Tais trabalhos colocam especial acento em outras relaçóes que se estabelecem entre produtores e consumidores, paralelamente e/ou em oposiçáo ao regime dominante, valendo-se de diferentes conceitos e perspectivas teóricas. ${ }^{3}$ Ao estudar fenômenos dessa envergadura, são acionadas ferramentas analíticas de diversos campos do conhecimento (sociologia da alimentaçâo, sociologia econômica, antropologia do consumo, geografia etc.) diante da transversalidade de tema tão complexo e relevante. Vejamos alguns eixos por onde transita o debate.

As cadeias curtas de suprimento (Renting, Marsden e Banks, 2003; Ilbery e Maye, 2005) são fundamentais para reduzir os efeitos deletérios do desperdício de energia das cadeias convencionais, medido em termos das distâncias que separam a esfera da produção e a do consumo final. A abordagem também é chamada de food miles (Smith et al., 2005). Alguns desses trabalhos destacam a natureza e a importância dos "sistemas agroalimentares localizado" (Sanz Cañada e Muchnik, 2011), sinteticamente referida como abordagem SIAL, enquanto outros falam de sistemas agroalimentares locais (Fonte, 2008; Karner, 2010). Há também os que se dedicam ao estudo de mercados de agricultores (Cleveland et al., 2014), sistemas de distribuição de produtos nos domicílios urbanos, ou box schemes (Brown, Dury e Holdsworth, 2009; Lamine, 2005), do esquema pick your own (colha você mesmo) (Aubry e Kebir, 2013), assim como a modalidade internet ordering systems (Milone, 2009) ou de compras via internet.

Outra vertente analisa as novas redes de cooperaçáo entre consumidores e produtores, onde os primeiros assumem um papel ativo em processos que vão muito além do objetivo de satisfazer necessidades alimentares imediatas e de consumir produtos saudáveis. Referimo-nos, nesse caso, ao que se considera "redes agroalimentares cívicas" (Renting,
Schermer e Rossi, 2012), que se apoiam sobre valores fundamentais como solidariedade, reciprocidade, democracia e cidadania. Ainda no terreno da diversidade de formas com que se exprime o debate sobre AFN, poder-se-ia mencionar o caso das community supported agriculture (Allen et al., 2003), onde há um compromisso tácito dos consumidores em apoiar material e simbolicamente os produtores que lhes fornecem o alimento, garantindo-lhes uma renda mensal ou pagamento antecipado dos produtos.

Analisando estudos realizados na Europa e nos Estados Unidos, é possível perceber que o debate não se concentra apenas na alternatividade em termos econômicos, mas também ocorre do ponto de vista da emergência de outros vetores, como no caso da segurança ambiental e equidade social (Goodman e Dupuis, 2002; Hendrickson e Heffernan, 2002).

Com base no aporte heurístico da teoria ator-rede ${ }^{4}$ (Long, 2001), tal perspectiva define AFN como um conjunto de práticas e relaçóes contraídas entre produtores e consumidores que emerge no contexto das abordagens pós-estruturalistas de análise do capitalismo, onde a categoria correspondente à alteridade adquire sentido diante de motivaçóes culturais e políticas dos consumidores (Goodman, 2003; Sassatelli, 2004). No âmbito europeu, as AFN são interpretadas não somente a partir do prisma das modificaçóes nos modelos de consumo, mas também do ponto de vista da contribuição que oferecem à construção de um novo paradigma de desenvolvimento rural, fundado em bases territoriais (Ploeg et al., 2000; Renting, Marsden e Banks, 2003) e voltado à revitalização das áreas rurais (Ventura e Milone, 2005; O’Connor et al., 2006).

Criado na Itália na segunda metade dos anos de 1980, e contando com aproximadamente 100 mil adeptos (Andrews, 2008) entre consumidores, degustadores, produtores e apoiadores em geral, o movimento Slow Food é uma plataforma de atuação centrada na importância transcendental do ato alimentar, no resgate e valorizaçáo de produtos tradicionais e na necessidade de redescobrir o prazer de uma boa refeição. Opóe-se, frontalmente, ao poder imposto pelos conglomerados agroalimentares mundiais e pela massificação da comida servida nas grandes cadeias mundiais (fast foods). 
O estudo realizado por Tregear (2011) propóe uma reflexão crítica sobre a agenda de pesquisa sobre AFN, identificando três grandes perspectivas ou orientaçóes teóricas na volumosa literatura que aborda esse tema. A primeira perspectiva se vale da economia política como campo de observação, tendo o enfoque marxista como fonte inspiradora na análise dos fatores macroestruturais do capitalismo global, sobretudo das forças neoliberais que se impóem sobre os indivíduos do ponto de vista de suas escolhas, padrôes de comportamento e condiçóes de existência. A segunda orientação corresponde aos estudos ligados à sociologia rural ou à perspectiva do desenvolvimento. Nesse caso, as AFN são vistas como resultado da construção social operada por agentes locais e como expressão de crenças, valores e motivaçóes que visam a benefícios sociais e econômicos a todos os atores implicados, sendo que tais estudos se situam no nível microanalítico. As formas de governança e a teoria de redes correspondem à terceira perspectiva dentro da literatura que aborda a dinâmica das AFN. O nível mesoanalítico corresponde, ainda segundo Tregear (2011), à dimensão escalar predominante nessa terceira perspectiva.

Para os objetivos que persegue este artigo, importa frisar que convergimos com Sivini (2008, p. 89) quando aponta as limitaçóes das abordagens usuais que se valem do conceito de AFN. No entendimento dessa autora, as categorias propostas por Renting, Marsden e Banks (2003) são úteis apenas no que tange ao conteúdo informativo que diferencia essas cadeias curtas de suprimento em relação às convencionais. Tal enfoque não dá conta, portanto, das motivaçóes, bem como das circunstâncias que os fizeram emergir. Outro problema heurístico associado à extensa literatura sobre o conceito de AFN é a tendência de enxergar esse termo em oposição ao sistema convencional. Se impóe, assim, uma visão maniqueísta que, no entendimento de Fonte (2010), desconhece que ambos os sistemas (convencional e alternativo) convivem dentro de um mesmo espaço econômico, havendo, entre ambos, um elevado grau de solapamento. Analisemos agora outra perspectiva por onde transita o debate sobre a construção social da qualidade agroalimentar.

\section{A dimensáo crítica e política do ato de consumo}

Enquanto campo de análise, o consumo convencionalmente esteve associado a uma conotação negativa no âmbito das ciências sociais. $\mathrm{Na}$ acepção marxista clássica (Marx, 1985), o desejo de consumir aparece vinculado ao fetichismo da mercadoria e ao processo de alienação do trabalhador. $\mathrm{Na}$ perspectiva weberiana, mostra-se ligado ao status ou prestígio, enquanto para Veblen (1988), pressupóe um caráter conspícuo ou ostentatório. Posteriormente, em Bourdieu (1979), tem-se o foco orientado ao sistema de gostos e preferências das pessoas, onde o ato de consumir é visto como um poderoso marcador de classe ou categoria social.

Ademais, a falta de interesse sobre a questão do consumo decorre, segundo Portilho (2009, p. 201), do viés moralista e moralizante das ciências sociais, em que pese o fato de que "trabalho e produção sempre foram considerados moralmente superiores ao consumo, fazendo com que a crítica e o julgamento moral das práticas de consumo acabassem se sobressaindo à análise sociológica deste fenômeno". Nesse sentido, $o$ ato de consumir deve ser entendido como instrumento de afirmação da identidade, muito além de sua mera função utilitária (Slater, 2005), dentro de um mundo que vive os efeitos da condição pós-moderna (Harvey, 2009), marcada pelo triunfo do efêmero, do ilusório e pela força dos simulacros.

Para Canclini (2010, p. 72), consumir deve ser compreendido como um exercício de cidadania e "como um lugar de valor cognitivo", daí a máxima de que o consumo serve para pensar e atuar, "renovadoramente, na vida social”. Destarte, poder-se-ia afirmar que se trata de um ato produtor de significados, que nos auxilia a ordenar o mundo à nossa volta, tornando-o compreensível (Douglas e Isherwood, 2006). ${ }^{5}$ Apoiar uma causa, como no caso de adquirir produtos de agricultores familiares ou de assentamentos da reforma agrária, leva implícita não somente a filiação dos indivíduos com o processo de produção e a natureza do produto, mas também uma forma de evidenciar a identidade de quem o consome, seguindo a perspectiva de Canclini (2010).

Consumido prosaicamente no dia a dia dos domicílios, ou de forma ritualizada, o alimento 
contém em si mesmo uma narrativa que é compartilhada por todos aqueles que, de uma forma ou de outra, veiculam essa mensagem. Esse é outro aspecto importante na medida em que exalta a ideia de pertencimento ou do esforço envidado pelas pessoas em seu afã de integração e compartilhamento de um sistema de valores. No entendimento de Portilho (2009, p. 210, aspas no original):

[...] o enfoque do consumo político não aborda consumidores engajados em movimentos sociais institucionalizados, tais como os movimentos de defesa dos direitos dos consumidores, movimentos anticonsumo ou movimentos pró-consumo responsável [...]. Ao contrário, esta abordagem enfatiza justamente aqueles atores sociais "não-organizados" e difusamente politizados que se situam entre o anonimato e a vontade de exercer um papel político, entre as preocupaçóes cotidianas da esfera privada e a vontade de participar de uma esfera pública mais ampla.

Essa forma de militância difusa remete nosso olhar para um leque de experiências que tanto podem envolver modalidades institucionalizadas de ação política como também estratégias de atuação que ultrapassam os canais convencionais de mediação. Em alguns casos, têm-se inclusive situaçôes de negação do marco de regulação instituído pelo Estado no que toca à segurança do que diariamente nos serve de alimento e satisfaçáo de necessidades.

Exemplo tácito dessa dinâmica pode ser visto na experiência italiana denominada Genuíno Clandestino. Trata-se de uma plataforma de ação política que critica não somente a atuação avassaladora dos grandes impérios agroalimentares, mas também dos mecanismos gerais de garantia da qualidade (selos, etiquetas etc.), que, segundo sua acepção, convencionalizam produtos e processos, impondo uma linguagem de signos que esconde mecanismos explícitos e implícitos de exclusão de camponeses e de outros grupos minoritários (mulheres, jovens etc.).

A expressão "genuinamente clandestino" exprime, de forma irônica, a repulsa aos valores que suportam a sociedade de consumo, bem como os instrumentos e regras que disciplinam o comércio e a distribuição de produtos agroalimentares, a exemplo dos dispositivos governamentais de controle e fiscalização. E, da crítica ao sistema agroalimentar, passa-se ao exercício de formas inovadoras de ação política. Por outra parte, o modelo de consumo alimentar que se impôs no mundo nos últimos cinquenta anos não é somente um sistema de produção, distribuição e consumo regido à escala global. É também um regime construído em cima de sofisticados instrumentos publicitários (Sivini, 2008, p. 71).

A posição dos atores implicados nesses processos reflete visóes nem sempre convergentes; o mesmo ocorre com a lógica que guia tais práticas. Algumas delas propugnam a busca de vias de fuga ao que consideram imposiçóes do modo de produção capitalista, sobretudo de sua face mais hedionda, qual seja, a do consumismo e dos efeitos a ele associados. Os "novos camponeses" ligados ao Genuíno Clandestino exemplificam essa tendência, claramente identificada com os movimentos anarquistas dos anos de 1970, especialmente no que tange aos princípios de autodeterminação e preservação ambiental. Outras, entrementes, predicam mudanças menos profundas, assumindo uma postura complementar ou superficial em termos de corrigir distorçóes mais aparentes, como é o caso da redução do nível de desperdícios, eliminação do uso de embalagens não renováveis, ou de assegurar o cumprimento da legislação trabalhista no processo de elaboração e distribuição do produto, haja vista o grande número de ocorrências de trabalho escravo e/ou de exploração da mão de obra de imigrantes.

Para os objetivos deste artigo, vale sublinhar algumas limitaçóes heurísticas desse tipo de abordagem, da mesma forma que fizemos com o caso do enfoque das redes agroalimentares alternativas. O maior deles é a ênfase atribuída ao consumo enquanto escopo e objeto de reflexão. Em outras palavras, há uma tendência a enfatizar a perspectiva do consumo em detrimento de outras dinâmicas que se entrelaçam na diversidade de experiências que eclodem na atualidade.

A tomada de consciência acerca dessas restrições ensejou o surgimento de neologismos que sintetizam esse esforço de ampliação do foco da abordagem. Gesualdi (1999) propôe o termo "prosumidor" "como uma versão sincrética de um ator social que personifica o papel de produtor e consu- 
midor. A visão linear da questão (produção-transporte-circulação-consumo) há que ser substituída por uma concepção que prima pela circularidade dos processos. O consumidor há que ser entendido como um produtor de condiçóes para que o alimento cumpra com a sua função social na geração de bens públicos, mas também pelo exercício de sua função simbólica via afirmação de valores como a solidariedade, reciprocidade, equidade, justiça social etc.

Ao conceber o consumidor como coprodutor (Petrini, 2005) ou pensar em processos de coprodução (Brunori, Rossi e Guidi, 2012), se reivindica um novo olhar, que postula uma clara ruptura com o reducionismo das abordagens usuais que não conseguem ir além das armadilhas da linearidade. Com efeito, a energia social dispendida nessas iniciativas varia segundo a força das conexóes que estabelecem e que, conjuntamente, movem o moinho da inovação institucional.

$\mathrm{Na}$ densa literatura italiana consultada sobre o assunto, há clara preferência pelo termo "consumo crítico" nas alusôes ao que, na literatura mundial, se conhece como consumo político. Em boa parte dos estudos, tal fenômeno é entendido como a prática de organizar os hábitos de compra e de consumo, priorizando os produtos que atendam a determinados requisitos de qualidade, incluindo as preocupaçóes com a sustentabilidade ambiental, o respeito aos valores éticos nas relações de trabalho e produção, bem como a identificação de eventuais práticas inadequadas ou condenadas por parte das empresas produtoras (Graziano, 2009a, p. 178).

Ainda assim, segundo a mesma fonte, a prática do consumo crítico pressupóe o exercício de um poder político, inclusive em termos de promover mudanças na administração pública local, regional e nacional. Trata-se de denunciar os impactos ecológicos das ações governamentais, de influir no sistema de aquisição de produtos e serviços, incluindo a promoção de "compras verdes" ou contratos públicos ecológicos. Em outras palavras, o consumo crítico tem um "valor político", não somente no sentido de incidir nas arenas públicas, mas de interferir nas escolhas das administraçóes, como no caso das compras institucionais de agricultores familiares para abastecer os restaurantes de escolas públicas e órgãos da administração italiana.
Essa visão é compartilhada por Yates $(2011)^{7}$ quando afirma que o consumo crítico implica boicotar a compra de mercadorias por razóes políticas, éticas ou ambientais, bem como exercitar uma "nova política". Como bem sublinhou Miller (1997), consumir é uma atividade que, quotidianamente, envolve a tomada de decisóes políticas e morais. Consoante esse aspecto, Canclini (2010) considera que, ante a degradação da política e a descrença nas instituiçōes, surgem, fortalecidos, outros modos de participação política e de identidade cultural. Todavia, há outros fatores e aspectos envolvidos. O caso que a seguir examinaremos reflete a natureza de um fenômeno social que atraiu nossa atenção não somente em virtude do número de indivíduos envolvidos, da dispersão espacial pelo território italiano, dos fatores e circunstâncias que ensejaram seu surgimento, mas pela relevância das questóes suscitadas.

\section{A experiência italiana dos Gruppi di Acquisto Solidale}

Os Gruppi di Acquisto Solidale (Grupos de Compras Solidárias), ou simplesmente GAS, nasceram no norte da Itália durante a década de 1990. O primeiro GAS surgiu em 1994, em Fidenza, província de Parma, regiáo de Emilia-Romagna. Dez anos mais tarde eram apenas 19, enquanto em 2006 contabilizavam 342, sendo que dois terços deles estavam situados no norte da Itália (Sivini, 2008, p. 77). De forma objetiva, um GAS pode ser entendido como um grupo de compras, sobretudo de produtos agroalimentares (frutas, legumes, derivados lácteos etc.), organizado espontaneamente e plenamente identificado com a abordagem política do ato de consumo. O crescimento numérico dessa experiência fez com que, já em 1997, surgisse a Retegas, uma rede que congrega os diversos grupos que inicialmente eclodiam apenas nas províncias setentrionais da Itália.

O número de participantes de um GAS é variável e sua lógica de operação é bastante flexível em função da diversidade de situaçôes e do nível de implicação de consumidores, produtores e demais atores participantes. A estratégia gasista, como destaca- 
ram Brunori, Rossi e Guidi (2012, pp. 9-10), pode ser sintetizada em quatro princípios: (1) consumo reflexivo, justiça social, sustentabilidade ambiental e uma nova acepção da qualidade; (2) solidariedade dentro do grupo e com os produtores com vistas à melhoria das condiçóes de trabalho; (3) socialização, entendida como a necessidade compartilhamento de ideias e de decisóes entre os participantes; (4) desenvolvimento de sinergias e relações sociais para reduzir o custo econômico da produçáo e distribuição de alimentos.

Esses princípios desembocam na adoção de determinados critérios organizativos, entre os quais, se destacam: (1) escolha de produtos sazonais e orgânicos; (2) logística de distribuição ancorada localmente; (3) apoio aos produtores locais e à venda direta dos produtos; (4) regularidade de abastecimento mediante acordos diretos com os produtores; (5) planejamento das compras e do consumo; (6) redução ou eliminação do volume de embala- gens; (7) redução da pressão exercida pela mídia e pela grande distribuição através do desenvolvimento de uma nova consciência sobre o ato de consumo; (8) controle social da qualidade dos produtos mediante informação compartilhada e diálogo com os produtores; (9) promoçẫo da confiança e cooperação dentro da rede.

Atualmente existem 1002 iniciativas de GAS em funcionamento (14 redes e 988 grupos constituídos), as quais se distribuem de forma reticulada, mas desuniforme, pela geografia italiana. Na Figura 1 , vemos que as regióes norte e centro concentram nada menos que $88,7 \%$ das iniciativas GAS de toda Itália. ${ }^{8}$

Sendo um típico canal curto de comercialização (filiera corta), a estratégia gasista passa por reduzir o food miles, ou seja, combater o desperdício de energia e de recursos que marca o regime que há décadas impera em todo o planeta, tal como vimos anteriormente. Mas, definitivamente, esse é apenas

Figura 1

Distribuição dos GAS na Itália Segundo Delimitação Geográfica (2015)
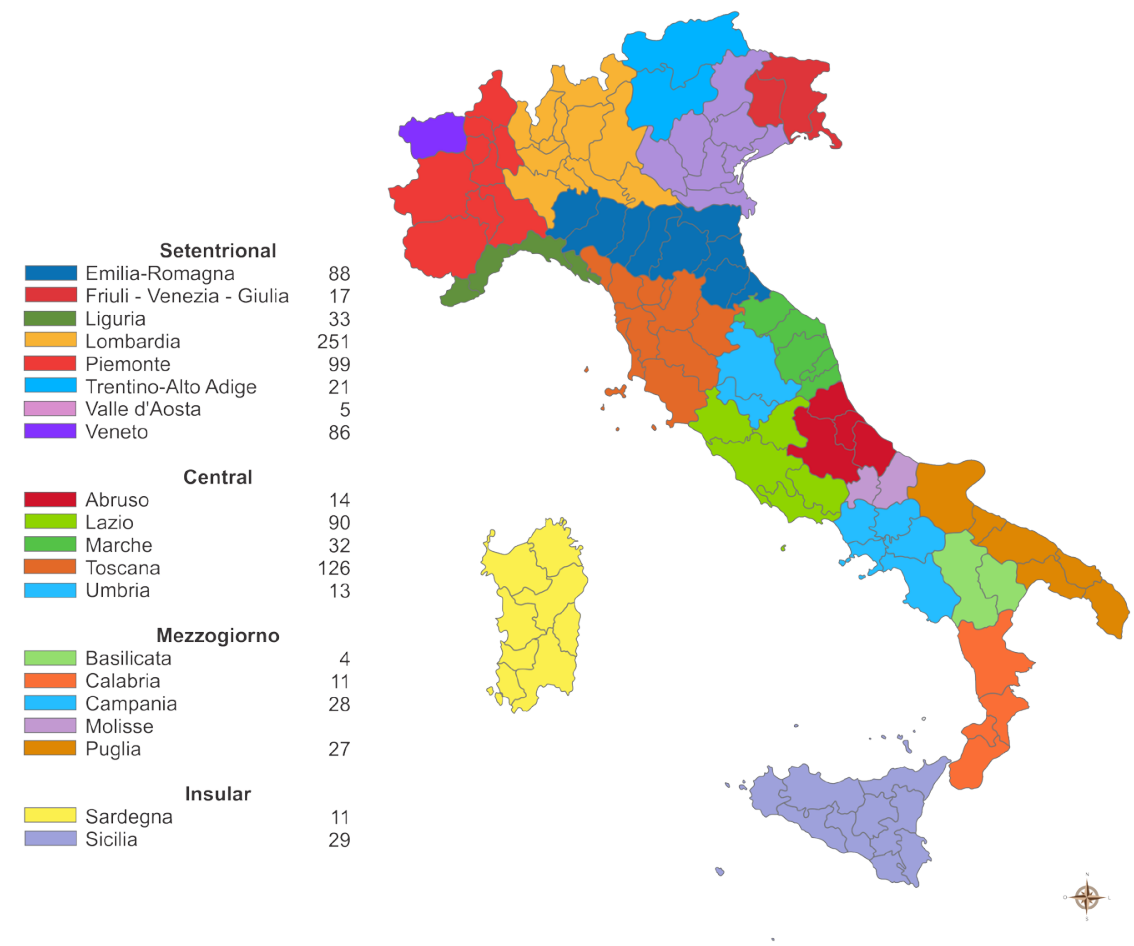

Fonte: Elaboração dos autores a partir da Rete di Economia Solidale (2015). 
um aspecto da questáo. O GAS nasce da necessidade de mudanças profundas no atual regime de abastecimento alimentar e não alimentar, tanto do ponto de vista individual como coletivo. Essa é a tarefa que nos toca desenvolver nos próximos parágrafos.

\section{O GAS como lócus de socialização e compartilhamento}

Nas seçóes precedentes, enfatizamos que o regime dominante de abastecimento alimentar se assenta no anonimato do consumidor, reduzindo a aquisição e o consumo de alimentos a uma operação banal e atomizada. Como bem destacou Portilho (2009, p. 201), o que designamos genericamente de movimento de consumidores engloba, ao menos, três categorias de movimento social. No primeiro caso, constam os movimentos de defesa dos direitos dos consumidores ou consumerismo, surgidos "como reação à situação de desigualdade entre fornecedores e consumidores".

No segundo caso, estão os movimentos anticonsumo, com sua crítica contumaz ao hedonismo e à sociedade de consumo. Por fim, tem-se os movimentos pró-consumo responsável, onde se busca "construir uma nova cultura de ação política através das práticas de consumo”. Nesse contexto, a estratégia gasista se apoia numa concepção frontalmente oposta ao regime hegemônico atual, ao predicar que o ato de consumir representa, sobretudo, um momento de reflexão, de socialização e de compartilhamento de experiências, de valores, de atitudes e de enriquecimento cultural.

Os depoimentos colhidos dos atores ligados ao GAS, incidiram na importância de adquirir a produção local e na necessidade de respeitar o ritmo das estaçóes e os ciclos da natureza, em lugar de adquirir produtos exóticos procedentes de lugares distantes, cujas condiçóes de produção são quase invariavelmente desconhecidas. Essa faceta do movimento gasista foi igualmente sublinhada no estudo realizado por Cassol e Schneider (2015), propondo uma aproximação contextual entre o caso da feira do pequeno produtor de Passo Fundo (RS) com a experiência GAS na região de Pisa (Toscana). No entendimento destes autores:
[...] a estratégia de sobrevivência dos produtores do GAS é centrada na qualidade, e a negociação e a construção desse atributo no interior da rede estão vinculadas à sazonalidade $\mathrm{e}$ à provisão/produção local dos alimentos consumidos, através dos quais características como "frescor", variedade, sabor e valor nutricional tornam-se essenciais (Cassol e Schneider, 2015 , p. 160 , aspas no original).

Como vimos anteriormente, o tempo presente é marcado pelo brutal distanciamento entre o mundo da produção e a esfera do consumo, mas também pela alta propensão das pessoas a consumirem refeições preparadas, pela decadência da tradição gastronômica, perda da diversidade alimentar e do conhecimento acumulado ao longo das geraçóes. Com efeito, a questão alimentar representa um ponto de vista privilegiado para entender as mutaçôes que atravessa o mundo moderno no momento presente. Segundo Martins (2014, p. 10), a "sociedade contemporânea caracteriza-se por uma nova pobreza, a pobreza de esperança que advém da redução do tempo da vida social ao agora, ao viver por viver, ao sobreviver".

O enfrentamento a esse tipo de dilema é um dos vetores que ensejam a arquitetura de um GAS. As falas dos entrevistados acentuaram o esforço envidado no sentido de edificar algo realmente distinto do regime atual, começando por restabelecer o contato direto com o agricultor. A justa remuneração do produtor é tão importante quanto a satisfação das necessidades imediatas do consumidor. Em outras palavras, o apreço pela causa se impóe sobre a ênfase estrita no preço do produto. A confiança no que está sendo adquirido prescinde, inclusive, da existência de certificação dos produtos orgânicos (Frandino, 2009, p. 112), contrariamente ao que ocorre nos canais convencionais de comercialização, onde esse requisito é absolutamente compulsório. A lógica de um GAS é, portanto, muito distinta à de outros canais de comercialização.

Nos países europeus, os episódios que envolvem a exploração da mão de obra de imigrantes são recorrentes. Não raras vezes, os baixos preços dos alimentos (frutas e verduras) praticados nos hipermercados ocultam a precarização das relações 
de trabalho. ${ }^{9}$ Fazer parte de um GAS confere um senso de responsabilidade e de pertencimento de indivíduos que investem muito mais tempo do que dinheiro em construir outras conexôes sociais. Forno (2009, pp. 40-41) sublinha que esse tipo de organização deve ser considerado uma "academia de democracia", onde se produz e se reproduz capital social. Isso porque o padrão atual de aprovisionamento de comida reduziu o mercado a um local onde se compra e se vende todo tipo de artigos em troca de dinheiro. Decididamente, a estratégia gasista visa romper com esse estigma ao fazer com que valores éticos (solidariedade, confiança, reciprocidade) sejam incorporados ao que, para a maioria das pessoas, não passa de um ato trivial e repetitivo.

Vários estudos analisaram o perfil de participantes dessa experiência. No GAS da cidade de Pavia, como frisou Wiener (2009, p. 99), predominariam consumidores com um nível médio-alto de cultura e de renda. Esses traços gerais se identificam com o GAS de Pisa, descrito por Brunori, Rossi e Guidi (2012), que integra em torno de 400 famílias. Os membros são geralmente ativistas de outras organizaçōes (comércio justo, associaçóes culturais), com idade média compreendida entre 30 e 60 anos e um nível médio-alto de escolaridade.

Um aspecto interessante parece ser o perfil dos produtores, que, não raras vezes, são "novos rurais" que passaram a viver em pequenas exploraçóes, onde a produção é baseada na diversificação de cultivos e num esforço de conciliar a tradição e a inovação nos processos produtivos (Brunori, Rossi e Guidi, 2012, p. 12). São frequentes os casos de pessoas que, havendo exercido ofícios tipicamente urbanos, retornam ao campo para administrar propriedades de pais ou avós que se aposentaram. $\mathrm{O}$ mesmo pode ser dito com relação a indivíduos que compaginam o exercício dessa forma de agricultura com outras ocupaçóes, configurando-se situaçôes típicas de exercício da pluriatividade. ${ }^{10}$ Desse modo, também é certo afirmar que a escolaridade dos produtores que participam de um GAS tende a ser mais alta que da média dos agricultores italianos em geral. As conclusóes a que chegou Sivini (2013, p. 51), investigando experiências de GAS na Itália meridional (Puglia e Sicília), convergem exatamente nessa direção:
Estes produtores, que definimos como críticos, possuem um nível médio-alto de conhecimento/competência que foi adquirido não somente através de uma formação educacional, mas também de experiências de trabalho e de viagens. Em diversos casos, têm-se indivíduos diplomados.

Mas é preciso sublinhar que a solidariedade não ocorre apenas nos limites estritos de um GAS. Ela também se impóe na relaçấo com outros GAS, especialmente quando se considera que essa experiência associativa atua como uma rede de redes que intercambiam, entre si, seus próprios produtos, de forma a fortalecer a diversidade do que é comercializado. Um GAS funciona geralmente em locais públicos, sobretudo em espaços cedidos pelas administraçóes locais ou regionais, bem como em garagens improvisadas, associaçôes culturais, clubes, igrejas etc. A chave de êxito, na acepção de Brunori, Rossi e Guidi (2012, p. 11), são os encontros mensais que envolvem os participantes. Não obstante, não se pode minimizar a importância da comunicação via internet e redes sociais, que otimizam o uso do tempo e dos recursos materiais, fazendo a informação fluir com extrema rapidez e flexibilidade.

\section{O GAS como ator politico}

A contribuição trazida por sociólogos contemporâneos, a exemplo de Giddens, Lash e Beck (2012), tem sido no sentido de mostrar que as transformaçôes sociais de nosso tempo (globalização da economia, aumento da mobilidade social etc.) alteram a percepçáo das pessoas, mostrando os riscos a que estamos expostos, mormente no que afeta o mundo da alimentaçáo em geral. Diante do colapso do Estado de bem-estar social quanto a sua capacidade oferecer segurança aos cidadãos, novas formas de solidariedade cobram relevância e visibilidade. Vislumbra-se, assim, o surgimento de novos movimentos sociais e organizações comunitárias praticantes de uma micropolítica ou de uma subpolítica (Beck, 1997). Esta pode ser traduzida na ideia de moldar a sociedade de baixo para cima, rompendo ou minimizando o espaço de influência da política tradicional. 
Esse marco geral guarda aderência com a filosofia gasista. Estudos como o de Carrera (2009) mostram que o crescimento numérico dos GAS se deve, em larga medida, a uma vontade frustrada de participação dos cidadãos italianos através dos partidos políticos tradicionais. Esse aspecto é flagrante nas entrevistas que realizamos com atores sociais participantes de GAS do mezzogiorno italiano e em vários estudos realizados em outras zonas desse país. ${ }^{11} \mathrm{O}$ cidadão vinculado a esse tipo de experiência, como bem definiu Forno (2009, p. 28), possui uma forte identificação com os princípios democráticos, mas uma desconfiança crescente no funcionamento das instituições e dos canais tradicionais de atuação política. Escândalos recorrentes de corrupção na vida social italiana parecem reforçar a percepção de que dificilmente as grandes mudanças poderão advir das altas esferas do poder central e/ ou regional.

A atuação política gasista pode ser valorada tanto em nível local, regional quanto nacional. No GAS da província de Pisa, Brunori, Rossi e Guidi (2012) relatam a luta travada contra a administração pública provincial para assegurar o local onde as feiras e as demais atividades acontecem dentro do espaço urbano. O exercício dessa mobilização no âmbito local está ligado, também, ao esforço de reformulação da política pública no que tange a temas relevantes, como é o caso do fornecimento de alimentação às escolas (Graziano, 2009b, p. 18). À preocupação com relação à qualidade do que é servido aos educandos, soma-se o interesse de modificar velhos esquemas de favorecimento a grupos econômicos que atuam nesse âmbito e de um regime baseado na lógica do menor preço, e não da melhor qualidade dos produtos ou do respeito aos imperativos da sustentabilidade.

No entendimento de Forno (2009, pp. 4950), o GAS funciona como um "laboratório de pensamento político”. As grandes causas incluem a defesa do território (urbano e rural) contra a especulação imobiliária, os métodos de cultivo convencional e seus efeitos deletérios sobre a natureza, a contaminação ambiental produzida pelas obras públicas e privadas, bem como a defesa da biodiversidade, do patrimônio cultural e paisagístico. A luta travada pelo Distrito de Economia Solidária do Parque Agrícola Sul de Milão contra o processo de urbanização (cementificazione) da área rural dessa metrópole italiana ilustra bem esse aspecto, tal como referem Papini e Vasciaveo (2009) e Corrado (2013), ao analisarem a luta contra o consumo do território - isto é, a mercantilização do espaço - e a busca por reconstruir, sobre novas bases, a relação campo-cidade.

No plano nacional, a Retegas exerce, também, certa influência. Um dos mais importantes logros dessa iniciativa foi a aprovação de uma emenda legal junto ao parlamento italiano, que estabelece que o GAS configura uma associação não lucrativa, com o objetivo de proporcionar compras coletivas e distribuição de produtos agroalimentares entre seus membros. Desse modo, trata-se de assegurar um tratamento fiscal diferenciado ao de outras experiências associativas. Segundo Brunori, Rossi e Guidi (2012, p.25), essa emenda legal é resultado de intenso lobby baseado numa aliança firmada com representantes do Partido Verde. Com efeito, trata-se de proteger o GAS da acusação de evasão de divisas, além de permitir que possa participar em projetos da administração pública através da assinatura de contratos de fornecimento de produtos agroalimentares. Mas há ainda outras arenas de poder onde o GAS exerce protagonismo político.

A certificação é atualmente um imperativo para a produção orgânica ou ecológica. Nesse sentido, para que um produto seja comercializado como tal, não basta ter sido produzido organicamente. Ele deve sofrer um processo de avaliação de conformidade, vulgarmente conhecido como certificação, sendo executado, comumente, por meio da contratação de empresas privadas. Ao valer-se de relaçóes de confiança entre produtores e consumidores, muitos dos participantes do GAS consideram pleonástico o recurso à certificação (Fonte e Salvioni, 2013, p. 89). Ademais de implicar dispêndio de dinheiro para os produtores e encarecer o preço final dos produtos, esse tipo de serviço contraria a lógica gasista de fomentar a confiança e reciprocidade entre os participantes (consumidores, produtores, agentes sociais etc.), dispensando a certificação e etiquetagem dos produtos.

Por outra parte, há sempre o risco de convencionalização de um processo que nasceu para ser 
singular. Todavia, não cabe dúvida de que debater a questáo da certificaçáo traz consigo uma oportunidade de enfrentar questóes que afetam o marco europeu de regulação nesse sentido, isto é, no que toca à certificação. Vale frisar que existem outras modalidades de certificaçáo, a exemplo dos sistemas participativos de garantia, em funcionamento no Brasil (Radomsky, 2009; Caldas, 2013), cuja lógica é diametralmente oposta ao padrão hegemônico nos países europeus, onde a certificação por terceira parte é absolutamente preponderante. Esse, indubitavelmente, é um dos temas que despertam a atenção dos participantes de um GAS. Questionar o padrão agroalimentar atual, os fartos subsídios concedidos à agricultura produtivista pela política agrária comunitária e os favores concedidos pelo Estado italiano à grande distribuição são objeto de intensos debates dentro dos espaços onde opera a experiência GAS em toda a Itália.

Com efeito, a organização de um GAS tanto deve ser vista como uma resposta crítica ao sistema agroalimentar industrial, que não assegura alimentos sãos aos consumidores, quanto ao modo de aprovisionamento de alimentos orgânicos, que visa atender mormente a um consumo elitizado e/ ou às demandas dos mercados de nicho. Essas são algumas das conclusóes de investigação realizada no GAS Roma por Fonte e Salvioni (2013, p. 94).

\section{O GAS como vetor da inovação social}

A aproximação realizada em solo italiano mostrou que as motivaçóes que impelem os indivíduos a cooperar em torno de um GAS decididamente vão muito além do esforço de organizar trocas comerciais entre produtores e consumidores. Coincidimos com Brunori, Rossi e Guidi (2012, p. 5) quando asseveram que tal iniciativa deve ser vista muito mais como laboratório para experimentar novas soluçóes para ingentes problemas de nossa sociedade do que como simples resultado da militância heroica de algumas minorias. E esses problemas não se resumem a um reposicionamento dos produtores familiares em mercados de nicho, onde um artigo ecologicamente produzido encontra o reconhecimento e retribuição de seus atributos diferenciais. Para Corrado (2013, p. 68), o GAS pode funcionar como uma estratégia eficaz e um estímulo para incitar a transição dos produtores em geral para a agricultura ecológica.

Convencionalmente, os produtores familiares de hortifrutigranjeiros vivem o que se poderia chamar de uma "dualidade perversa" no que tange aos processos produtivos levados a efeito dentro de suas exploraçóes agropecuárias. Essa se manifesta na oposição entre o que é plantado para a venda e o que é plantado para o consumo próprio. No primeiro caso, a preocupação é com o resultado econômico do negócio, onde o uso de produtos de síntese (incluindo agrotóxicos) é recorrente para assegurar uma boa colheita e o retorno do investimento. Já no caso da produção para o autoconsumo, a preocupação é outra. Trata-se de prover a própria mesa com artigos de qualidade e que não ofereçam riscos à saúde de quem os consome, incluindo a família do produtor. Em outras palavras, trata-se aqui de libertar o agricultor desse inquietante dilema. Os produtos que entrega no GAS de que participa são os mesmos que consome em sua casa. A inovação social está justamente em romper essa dinâmica espúria que obrigou produtores e consumidores a gravitarem em torno de mundos tâo distintos.

Baseados nas teorias de gestão da transição, Brunori, Rossi e Guidi (2012) apontam a existência de dois tipos de inovação social, quais sejam, a inovação incremental e a inovação radical. A primeira delas é baseada em aperfeiçoamentos graduais (step by step), guiados pelo processo de aprendizagem e conhecimentos obtidos dentro de determinado paradigma. Já no caso da inovação radical, estamos diante de novos paradigmas e, consequentemente, de novos conhecimentos e recursos. No caso em tela, a inovação incremental limitar-se-ia a mudanças nos processos produtivos que reduzissem os impactos ambientais pela via da substituição de insumos químicos por insumos biológicos ou mesmo por sistemas de produção mais sustentáveis. Mas na acepção radical da inovaçáo social, a questão adquire uma dimensão muito mais profunda, dado que se trata de modificar tanto os processos de produção quanto os sistemas de transporte e distribuição de alimentos. Nesse sentido, o espaço do GAS adquire uma dimensão cognitiva, onde a livre circu- 
lação de informaçóes e conhecimentos leva a um outro patamar de compreensáo da realidade por parte daqueles que dele fazem parte.

Em outras palavras, poder-se-ia admitir que o GAS representa uma inovação que tanto pode significar a mudança de comportamento de um número crescente de consumidores que se filiam a essa iniciativa, como também uma transformação mais profunda, que evoca outra narrativa que desafia todo um regime de produção, transporte, circulação e abastecimento de produtos agroalimentares, regido pela ênfase no produtivismo, padronização, anonimização e desterritorialização dos processos produtivos.

Convergimos com Cassol e Schneider (2015) quando reiteram que a atuação em rede do GAS propicia intensa troca de informaçóes, assim como compartilhamento de conhecimentos entre os integrantes e as instituiçóes participantes, aspectos estes que contribuem para um processo de enraizamento que diverge de outras formas de comércio e produção alimentar. Há conexóes com outras redes, incluindo o exemplo de elaboradores de produtos tradicionais, como no caso do queijo parmigiano reggiano, (Cassol e Schneider, 2015, p.159). Na investigação que realizamos, foram identificadas "sinapses sociais" com outras redes, como o já mencionado movimento Slow Food ou da experiência correspondente ao projeto Campagna Amica. Trata-se, no último caso, de iniciativa liderada pela Coldiretti, a maior confederação de Agricultores Familiares da Itália, que, em boa medida, comercializa os produtos em lojas especializadas (botteghe) situadas no centro de médias e grandes cidades de todo o território italiano. O slogan do Campagna Amica é fomentar o que denominam "filiera agroalimentare italiana", ou seja, uma cadeia agroalimentar $100 \%$ italiana. Esse entrelaçamento mostra a diversidade de conexóes possíveis mobilizadas pela iniciativa GAS, tanto do ponto de vista horizontal quanto vertical.

\section{Alguns desafios da estratégia $G A S$}

Os dados que apresentamos na Figura 1 evidenciaram as grandes diferenças existentes em termos da distribuição geográfica dos GAS dentro do território italiano. Fato é que nada menos que
61,1\% das iniciativas de GAS estáo situadas na parte setentrional da Itália. Em contrapartida, 27,6\% concentram-se na região central, 7,3\% no mezzogiorno (zona meridional) e apenas $4 \%$ na Itália insular (Sardenha e Sicília). Várias poderiam ser as causas que ensejam esse quadro, como o fato dessa iniciativa haver iniciado há mais de duas décadas numa região (Emilia-Romagna) considerada uma das mais desenvolvidas e prósperas da Itália.

Em maior ou menor medida, vale frisar que a realidade atual mostra que as desigualdades econômicas e sociais entre o norte e o sul da Itália se mantêm em pleno século XXI. Trata-se de tema que mereceu amplo destaque na obra seminal de Putnam (1996), ${ }^{12}$ ao enfatizar que, nas regióes setentrionais desse país, os cidadãos são atuantes e imbuídos de espírito público, bem como pela existência de relaçôes políticas mais igualitárias em meio a uma estrutura social ancorada na confiança e na colaboração. Contrariamente, nas regiôes meridionais, prepondera uma política verticalmente estruturada, onde a vida social se encontra baseada na fragmentação, no isolamento e numa cultura política impregnada pela desconfiança.

Tais discrepâncias, ainda segundo Putnam, seriam cruciais para compreender as diferenças no desempenho econômico das regióes italianas. As virtudes da comunidade cívica exaltadas por Putnam são o produto de uma longa tradição histórica. Destarte, segundo alguns de seus maiores críticos (Tarrow, 1996), ao tentar explicar as diferenças entre o norte e sul italiano, Putnam tratou de forma superficial e seletiva a complexa e milenar história italiana, elegendo apenas dados e informaçóes que fizessem confirmar uma posição preconcebida. Explorar os meandros dessa questão extrapola totalmente os objetivos deste artigo.

O fato é que o processo de criação de iniciativas GAS no sul da Itália é bastante recente e ainda em fase de construçấo. Outro aspecto evidenciado no contato com a realidade concreta do mezzogiorno é certo grau de precariedade e improvisação no funcionamento dessas experiências, se comparado com a organizaçáo reinante nas regióes do centro e, sobretudo, do norte italiano. Os vários estudos que evocamos mostram que os participantes dos GAS possuem, em geral, nível cultural e grau de escolaridade mais elevados, fato 
que alimenta a ideia de que exista certa elitizaçáo do processo, aspecto este que requer maior aprofundamento em estudos futuros.

Outro aspecto que aflorou no contato direto com a realidade foi a grande diversidade dos atores ligados ao GAS do ponto de vista da ocupação, condição laboral e formas de atuação. Nas reunióes realizadas periodicamente, há um espaço de interação onde ocorrem trocas culturais, compartilhamento de informaçôes e busca de soluçôes em torno dos mais diversos temas da atualidade. Além da questão da produção e comercialização local de alimentos, há outras questôes em debate, como as formas de apoio e solidariedade às organizaçóes do Terceiro Mundo, o combate aos desperdícios, a contaminação dos recursos naturais e, mais recentemente, a situação dos imigrantes africanos, incluindo a necessidade de acolhimento dessas pessoas que chegam massivamente às costas italianas. Contudo, não raras vezes, percebemos certa atomização das energias diante da amplitude de temas que formam parte do horizonte de atuação dos atores ligados ao movimento GAS.

Além disso, outro desafio importante tem a ver com o fato de serem recorrentes os casos de produtores do mezzogiorno que fornecem produtos comercializados nos GAS das regióes do norte e centro, subvertendo a lógica de promover a produção local e privilegiar as relaçóes face a face entre os participantes das iniciativas GAS. Essa dinâmica não favorece uma mudança substancial na condição subordinada dos produtores do sul, reproduzindo as aludidas debilidades das estruturas locais e regionais de comercialização da produção agroalimentar. A pesquisa realizada por Sivini (2013, p. 56) convergiu claramente nessa direção. Além disso, acrescenta que, nas regióes meridionais da Itália, a constituição de redes agroalimentares alternativas envolve açóes lideradas muito mais por agricultores do que propriamente por consumidores. Os agricultores do sul (Calábria, Campania, Puglia etc.), desse modo, buscam evitar o abandono da terra por falta de oportunidades e os conhecidos problemas estruturais ligados a dificuldades de escoamento da própria produção.

\section{Consideraçóes finais}

Uma das célebres frases atribuídas a Bertrand Russel é que a economia é a ciência que explica como os indivíduos fazem escolhas, enquanto a sociologia dedica-se a mostrar que não há escolhas a fazer (Abramovay, 2004, p. 37). Todavia, as quatro últimas décadas refletem mudanças importantes, que rompem com os esquemas usuais de compreensão da realidade. Nesse plano, cresce o entendimento de que os mercados devem ser vistos como lócus de interação social, espaço de convergência e exercício da liberdade.

No Brasil, o debate sobre a dinâmica das redes agroalimentares alternativas e experiências de consumo político é ainda incipiente. No primeiro caso, deixamos evidenciado o entendimento de serem elas a expressáo de uma tendência em que os mercados assumem a forma de uma arena pública, de um espaço de reivindicaçóes por mudanças e objeto de exercício da democracia no que tange à produção, abastecimento e consumo agroalimentar.

Ressaltamos também a inconsistência de boa parte dos estudos realizados sobre a dinâmica das redes agroalimentares alternativas, sobretudo no que tange à necessidade de compreender tais processos para além da visão dicotômica que coloca o alternativo e o convencional em planos distintos e opostos. Ao analisar a questão, exaltamos o privilégio atribuído à dimensão agrícola e agrária nos estudos rurais, bem como a necessidade de ampliar e renovar um campo de observaçáo - o consumo alimentar - que demanda um olhar transversal diante da complexidade dos elementos envolvidos.

A experiência GAS desnuda um fenômeno que nasce da atuação destacada de consumidores italianos inconformados com as imposiçóes da grande distribuição de alimentos e com um padrão de agricultura que gera externalidades negativas de grande calado. O elevado grau de flexibilidade e informalidade desse tipo de estratégia tanto pode ser visto como um ponto forte, ao fugir do rigor de fórmulas preconcebidas e dos esquemas convencionais de abastecimento, como uma de suas debilidades. No último caso, há limites decorrentes da frágil participação dos agricultores nas arenas decisórias, que acabam sendo lideradas pelos consumidores. No 
mezzogiorno italiano, por razóes estruturais, tal movimento se mostra mais frágil e incipiente diante da menor densidade do tecido social, se comparado com as zonas setentrionais. Destarte, boa parte da produção alimentar gerada no sul acaba por abastecer o norte e centro da Itália, em lugar de consolidar a estratégia GAS nos próprios locais de origem.

De todo modo, o fenômeno em tela contraria a tese de que inexistem escolhas a serem feitas pelos consumidores, bem como que estas seriam guiadas por critérios estritamente econômicos ou por intermédio de uma lógica hedonista centrada na valorização de atributos distintivos, que remetem a singularidades dos produtos. A aprovação de uma emenda legal junto ao parlamento, assegurando um tratamento fiscal diferenciado ao de outras experiências associativas italianas, é uma clara demonstração do protagonismo político exercido, no plano nacional, pelo movimento gasista.

Entrementes, há diversas frentes em que a atuação de seus membros se faz presente, sobretudo no que se refere à luta contra a especulação imobiliária, o consumo do território, a urbanização de áreas rurais ou mesmo a contaminação dos recursos naturais pelas indústrias e pela agricultura produtivista. No repertório de açóes, consta a crítica contumaz à cheap food policy (política de alimentos baratos) praticada pelas grandes cadeias de distribuição, que invariavelmente escondem mecanismos de exploração de pequenos produtores e de trabalho escravo. Estes e outros aspectos fazem da estratégia GAS um lócus de exercício de outra política, que busca enfrentar os desafios da sociedade de risco em que estamos imersos.

Não menos importante é o esforço envidado pelos atores sociais no sentido de elaborar uma narrativa identificada com os princípios do consumo crítico, da reciprocidade, confiança, justiça social e da construção social da sustentabilidade. A vontade frustrada de participação dos cidadáos italianos nos canais convencionais da política nacional e o afã de construir rotas de fuga às imposiçôes da grande distribuição de alimentos fazem da experiência GAS não somente um marco de referência sobre a natureza das redes agroalimentares alternativas, mas um motor de inovação social e de atuação política de consumidores engajados na busca de mudanças diante de um regime agroalimentar em crise.

\section{Notas}

1 Existe ampla controvérsia na terminologia empregada nesse âmbito, sendo este um terreno de disputas tanto do ponto de vista acadêmico quanto ideológico e político. A agricultura orgânica é entendida como uma forma de produzir que exclui o uso de produtos de síntese (adubos sintéticos, agrotóxicos etc.). Todavia, no caso da agroecologia, tais imperativos técnicos são acrescidos de requisitos primordiais, como o respeito às justas relaçóes de trabalho nos diversos elos que unem a produçáo ao consumo, bem como em termos dos compromissos éticos mais amplos com a preservação dos recursos naturais. Com isso, poder-se-ia admitir que todo produto agroecológico é orgânico, mas a recíproca não é verdadeira. A legislação brasileira optou pelo uso do termo orgânico, enquanto na Itália e França a ênfase recai sobre o termo biológico nas alusóes a essa forma de agricultura. Neste artigo, consideramos os termos como equivalentes, admitindo que essa discussão, ainda que pertinente, extrapola nossos objetivos.

2 AFN é a abreviação em língua inglesa para Alternative Food Network, já consagrada na literatura internacional.

3 No Brasil, ver a propósito Wilkinson (2008), obra que analisa a construçáo social de novos mercados e redes implementadas pelas forças ligadas à dinâmica da agricultura familiar.

4 A obra do filósofo, sociólogo e antropólogo francês Latour (2012) destaca que a sociedade vem sendo substituída por redes sociotécnicas, sendo que os atores (humanos e não humanos) estão ligados a uma rede social de elementos (materiais e imateriais), que interagem recíproca e constantemente.

5 Há uma profícua e densa literatura sobre a questáo dos bens e da cultura material. A abordagem de Appadurai (2006) sugere que a circulação de mercadorias pode ser analisada segundo o prisma das trocas de dádivas e presentes, admitindo que há espírito nas mercadorias. Por outro lado, Kopytoff (2006) entende que mercadorias devem ser analisadas como processos cognitivos e culturais, e não somente como coisas produzidas, circuladas e trocadas por dinheiro. Miller (1995), por seu turno, exalta o potencial ativo do consumidor como (re)socializador das mercadorias.

6 Tradução livre do termo em italiano prosumatori ou prosumer em inglês. Na área energética, o termo é usado para o cidadão urbano que, ademais de consumidor, assume o papel de produtor de energia, como no caso do sistema fotovoltaico.

7 Outros trabalhos trouxeram relevantes contribuiçôes 
a esse debate, como é o caso de Micheletti e McFarland (2012) e Nutzenadel e Trentmann (2008).

8 Esse aspecto é deveras relevante para os objetivos deste artigo; assim será retomado ao final desta seção.

9 Essa explosiva questâo foi tema de documentário intitulado I mandarini e le olive non cadono dal cielo (As bergamotas e olivas não caem do céu), que aborda a exploração da mão de obra de africanos por parte das empresas ligadas às grandes cadeias de distribuição. Em 2010, houve uma violenta rebelião na cidade de Rosarno (Calábria), duramente reprimida pelas forças do Estado italiano.

10 A pluriatividade corresponde às situaçóes que envolvem, em boa medida, a conciliação da condição de agricultor com o exercício de outras atividades remuneradas ou profissóes, desvinculadas da produção agropecuária. No Brasil, esse tema foi abordado nas pesquisas do Projeto Rurbano. Ver, a propósito, Carneiro (1998), Anjos (2003) e Schneider (2003).

11 A plataforma Libera Terra é uma marca que agrupa em torno de si várias cooperativas que produzem em terrenos confiscados de organizaçóes mafiosas da Sicília, Puglia, Campania e Calábria, onde são assentados, sobretudo, imigrantes africanos, sendo uma ação organizada essencialmente por organizaçóes e movimentos sociais que lutam pela dignidade humana e proteçáo do espaço natural.

12 Os estudos realizados ao longo de duas décadas sobre as diferenças econômicas e sociais entre as regióes italianas serviram de base para que Putnam (1996) elaborasse aquela que é considerada a sua mais importante e ambiciosa obra (Comunidade e democracia: a experiência da Itália moderna), sendo referência obrigatória nos estudos sobre capital social. Regióes mais desenvolvidas, marcadas pelo engajamento cívico, são aquelas que possuem alta densidade de associações e onde há relações sociais de reciprocidade.

\section{BIBLIOGRAFIA}

ABRAMOVAY, R. (2004), “Entre Deus e o Diabo: mercados e interação humana nas ciências sociais". Tempo Social, 16 (2): 35-64.

ALLEN, P. et al. (2003), "Shifting places in the agrifood landscape: the tectonics of alternative agrifood initiatives in California”. Journal of Rural Studies, 19: 61-75.

ANDREWS, G. (2008), The Slow Food story: poli- tics and pleasure. Londres, Pluto Press.

ANJOS, F. S. (2003), Agricultura familiar, pluriatividade e desenvolvimento rural no Sul do Brasil. Pelotas, EGUFPEL.

APPADURAI, A. (2006), The social life of things. Commodities in cultural perspective. Cambridge, Cambridge University Press.

AUBRY, C. \& KEBIR, L. (2013). "Shortening food supply chains: a means for maintaining agriculture close to urban areas? The case of the French metropolitan area of Paris". Food Policy, 41: 85-93.

BECK, U. (1998), ¿Qué es la globalización? Falacias del globalismo, respuestas a la globalización. Trad. de B. Moreno e M. R. Borràs. Barcelona, Paidós Ibérica.

BOURDIEU, P. (1979), La distinction: critique sociale du jugement. Paris, Minuit.

BROWN, E.; DURY, S. \& HOLDSWORTH, M. (2009), "Motivations of consumers that use local, organic, fruit and vegetable box schemes in Central England and Southern France". Appetite, 53: 183-188.

BRUNORI, G.; ROSSI, A. \& GUIDI, F. (2012), "On the new social relations around and beyond food: analyzing consumer's role and action in Gruppi di Acquisto Solidale (Solidary Purchasing Groups)". Sociologia Ruralis: 52 (1): 1-30.

CALDAS, N. V. (2013), A certificação de produtos orgânicos no Brasil e na Espanha. Pelotas, Editora UFPel.

CANCLINI, N. G. (2010), Consumidores e cidadãos: conflitos multiculturais da globalização. Rio de Janeiro, Editora da UFRJ.

CARNEIRO, M. J. (1998), Camponeses, agricultores e pluriatividade. Rio de Janeiro, Contra Capa.

CARRERA, L. (2009), "I Gruppi di Acquisto Solidale: una proposta solida nella società liquida”. Participazione e Conflito, 3: 95-122.

CASSOL, A. \& SCHNEIDER, S. (2015), "Produção e consumo de alimentos: novas redes e atores". Lua Nova, 95: 143-177.

CLEVELAND, D. et al. (2014), "Local food hubs for alternative food systems: a case study from Santa Barbara County, California”. Journal of Rural Studies, 35: 26-36.

CONTRERAS, J. (2002), "Alimentación y socie- 
dad: sociología del consumo alimentario en España”, in C. Gómez y J. J. González (eds.), Agricultura y sociedad en el cambio de siglo, Madri, McGraw-Hill.

CORRADO, A. (2013), "Nuovi contadini e sistemi alimentari sostenibili: il DESR Parco Agricolo Sud Milano", in S. Sivini e A. Corrado (orgs.), Cibo Locale: percorsi innovativi nelle pratiche di produzione e consumo alimentare, Napoli, Liguore.

DÍAZ MÉNDEZ, C. \& ESPEJO, I. G. (2014), "La mirada sociológica hacia la alimentación: análisis crítico del desarrollo de la investigación en el campo alimentario". Política y Sociedad, 51 (1): 15-49.

DOUGLAS, M. \& ISHERWOOD, B. (2006), $O$ mundo dos bens: para uma antropologia do consumo. Rio de Janeiro, Editora da UFRJ.

FONTE, M. (2008), "Knowledge, food and place: a way of producing, a way of knowing". Sociologia Ruralis, 48 (3): 200-222.

(2010), "Food relocalisation and knowledge: dynamics for sustainability in rural areas", in M. Fonte e A. G. Papadopoulos (orgs.), $\mathrm{Na}$ ming food after places: food relocalization and knowledge dynamics in rural development, Farnham, Ashgate.

FONTE, M. \& SALVIONI, C. (2013), "Cittadinanza ecologica e consumo sostenibile: dal biologico ai Gruppi di Acquisto Solidale", in S. Sivini e A. Corrado (orgs.), Cibo locale: percorsi innovativi nelle pratiche di produzione e consumo alimentare, Napoli, Liguore.

FORNO, F. (2009), "Consumatori in 'movimento': il consumo critico come forma di partecipazione politica", in P. Graziano (org.), GASP: Gruppi di acquisto solidale e partecipativo, Milano, Punto Rosso.

FRANDINO, M. (2009), "Gas Casale Monferrato, Alessandria”, in P. Graziano (org.), GASP: Gruppi di Acquisto Solidale e Partecipativo, Milano, Punto Rosso.

GESUALDI, F. (1999), Manuale per un consumo responsabile: dal boicottaggio al comercio equo e solidale. Milano, Feltrinelli.

GIDDENS, A.; LASH, S. \& BECK, U. (2012), Modernização reflexiva: política, tradição e estética na ordem social moderna. São Paulo, Edito- ra da Unesp.

GOODMAN, D. (2003), “The quality 'turn' and alternative food practices: reflections and agenda". Journal of Rural Studies, 9: 1-7.

GOODMAN D. \& DUPUIS, M. (2002), "Knowing food and growing food: beyond the production-consumption debate in the sociology of agriculture". Sociologia Ruralis, 42 (4): 5-22.

GRAZIANO, P. (2009a), "I Gas: un movimento di pressione", in P. Graziano (org.), GASP: Gruppi di Acquisto Solidale e Partecipativo, Milano, Punto Rosso.

. (2009b), GASP: Gruppi di Acquisto Solidale e Partecipativo. Milano, Punto Rosso.

HARVEY, D. (2009). Condição pós-moderna. 18. ed. São Paulo, Loyola.

HENDRICKSON, M. K. \& HEFFERNAN, W. D. (2002), "Opening spaces through relocalization: locating potential resistance in the weaknesses of the global food system". Sociologia Ruralis, 42 (4): 347-369.

ILBERY, B. \& MAYE, D. (2005), "Alternative (shorter) food supply chains and specialist livestock products in the Scottish-English borders". Environment and Planning A, 37: 823-844.

KARNER, S. (2010). Local food systems in Europe: case studies from five countries and what they imply for policy and practice. Graz, IFZ.

KOPYTOFF, I. (2006), "The cultural biography of things: commoditization as process", in A. Appadurai (org.), The social life of things: commodities in cultural perspective, Cambridge, Cambridge University Press.

LAMINE, C. (2005), "Settling shared uncertainties: local partnerships between producers and consumers". Sociologia Ruralis, 45 (4): 324-345.

LANGREO, A. (1988), La agricultura contractual. Madri, COAG.

LATOUR, B. (2012), Reagregando o social. Bauru/ Salvador, Edusc/EdUFBA

LONG, N. (2001), Development sociology: actor perspectives. Londres, Routledge.

MARTINS, J. S. (2014), Uma sociologia da vida cotidiana. São Paulo, Contexto.

MARX, K. (1985), O capital: crítica da economia política. São Paulo, Nova Cultural, Livro 1, t. 2. 
MICHELETTI, M. \& MCFARLAND, A. S. (2012), Creative participation, responsibility: taking in the political word. Londres, Paradigm.

MILLER, D. (1995), "Consumption and commodities". Annual Review of Anthropology, Londres, 24: 141-161.

(1997), "Could shopping ever really matter?", in P. Falk and C. Campbell (orgs.), The shopping experience, Londres, Sage.

MILONE, P. (2009), Agriculture in transition: a neo-institutional analysis. Assen, Royal van Gorcum.

NUTZENADEL, A. \& TRENTMANN, F. (2008), Food and globalization, consumption, markets and politics in the modern word. Oxford/Nova York, Berg.

O'CONNOR, D. et al. (2006), Driving rural development: policy and practice in seven EU countries. Van Gorcum, Assen.

PAPINI, M. \& VASCIAVEO, V. (2009), "Gas Baggio, Milano”, in P. Graziano (org.), GASP: Gruppi di Acquisto Solidale e Partecipativo, Milano, Punto Rosso.

PETRINI, C. (2005), Buono, pulito e giusto. Torino, Einaudi.

PLOEG, J.D. (2008), Camponeses e impérios alimentares: lutas por autonomia e sustentabilidade na era da globalização. Porto Alegre, Editora da UFRGS.

PLOEG, J. D.; RENTING, H.; BRUNORI, G.; KNICKEL, K.; MANNION, J.; MARSDEN, T.; ROEST, K.; SEVILLA-GUZMÁN, E.; VENTURA, F. (2000), "Rural development: from practices and policies towards theory". Sociologia Ruralis, 40 (4): 391-408.

PORTILHO. F. (2005), Sustentabilidade ambiental, consumo e cidadania. Sáo Paulo, Cortez.

(2009), "Novos atores no mercado: movimentos sociais econômicos e consumidores politizados". Política \& Sociedade, 8 (15): 199-224.

PUTNAM, R. D. (1996), Comunidade e democracia: a experiência da Itália Moderna. Rio de Janeiro, Editora FGV.

RADOMSKY, G. F. (2009), "Práticas de certificação participativa na agricultura ecológica: rede, selos e processos de inovação". Revista Ideas, 3: 133-164.
RENTING, H.; MARSDEN, T. \& BANKS, J. (2003), "Understanding alternative food networks: exploring the role of short food supply chains in rural development". Environmental \& Planning, 35 (3): 393-411.

RENTING, H.; SCHERMER, M. \& ROSSI, A. (2012), "Building food democracy: exploring civic food networks and newly emerging forms of food citizenship". International Journal of Sociology of Agriculture and Food, 19 (3): 289-307.

RETE DI ECONOMIA SOLIDALE (2015), Archivio organizzazioni di economia solidale. Disponível em http://www.economiasolidale.net/content/gruppi-dacquisto-solidale-gas, consulta em 18 nov. 2015.

SANZ CAÑADA, J. S. \& MUCHNIK, J. (2011), "Ancrage et identité territoriale des systèmes agroalimentaires localisés". Économie Rurale, 322: 1-83.

SASSATELLI, R. (2004), "L'alimentazione: gusti, pratiche e politiche". Rassegna Italiana di Sociologia, 45 (4): 475-492.

SCHNEIDER, S. (2003), "Teoria social, agricultura familiar e pluriatividade”. RBCS, 18 (51): 99-192.

SCOTT, J. (2006), Sociologia: conceitos-chave. Rio de Janeiro, Zahar.

SIVINI, S. (2008), Intrecciare reti: agricultori biologici, gruppi di acquisto solidali, turisti responsabili. Catanzaro, Rubbettino.

. (2013), "Pratiche di produzione (alimentare) critica nel Mezzogiorno d'Italia". in S. Sivini e A. Corrado (orgs.), Cibo locale: percorsi innovativi nelle pratiche di produzione e consumo alimentare, Napoli, Liguore.

SLATER, D. (2005), "The sociology of consumption and lifestyle", in C. Calhoun et al. (orgs.), The Sage Handbook of Sociology, Londres, Sage.

SMITH, A. et al. (2005), The validity of food miles as an indicator of sustainable development. Londres, Defra.

TARROW, S. (1996), "Making social science work across space and time: a critical reflection on Robert Putnam's Making Democracy Work". The American Political Science Review, 90 (2): 389-397. 
TREGEAR, A. (2011), "Progressing knowledge in alternative and local food networks: critical reflections and a research agenda". Journal of Rural Studies, 27 (4): 419-430.

VEBLEN, T. (1988), A teoria da classe ociosa: um estudo econômico das instituiçóes. São Paulo, Nova Cultural.

VENTURA, F. \& MILONE, P. (2005), Innovatività contadina e sviluppo rurale. Milano, Franco Angeli.

WIENER, R. G. (2009), "Associazione Gas Pavia.", in P. Graziano (org.), GASP: Gruppi di Acquisto Solidale e Partecipativo, Milano, Punto Rosso.

WILKINSON, J. (2008), Mercados, redes e valores. Porto Alegre, Editora da UFRGS.

YATES, L. S. (2011), "Critical consumption. Boycotting and buycotting in Europe". Journal of European Societies, 13 (2): 191-217. 


\section{UMA RESPOSTA SÓLIDA A UM REGIME AGROALIMENTAR EM CRISE: O FENÔMENO GAS NA ITÁLIA}

\section{Flavio Sacco dos Anjos e \\ Nadia Velleda Caldas}

Palavras-chave: Redes agroalimentares alternativas; Economia solidária; Consumo político; Consumo crítico; Itália.

Este artigo se insere no debate mundial sobre a dinâmica das redes agroalimentares alternativas. $\mathrm{O}$ objetivo central do trabalho consiste em analisar a constituição e funcionamento dos Gruppi di Acquisto Solidale, considerada atualmente como a mais importante experiência de consumo político da Itália. O estudo se baseia em entrevistas em profundidade realizadas com diversos atores ligados a essa iniciativa (produtores, consumidores, técnicos etc.), cujo foco é mostrar que náo se trata apenas de uma modalidade singular de compra e venda de produtos agroalimentares, mas de um movimento mais amplo que desafia o mainstream da produção, distribuiçấo e consumo agroalimentar vigente em todo o planeta. A contribuição do trabalho está em suscitar a reflexão em torno da importância desses processos enquanto objeto de observaçáo sociológica, em meio aos efeitos decorrentes dos escândalos agroalimentares da atualidade.

\section{A SOLID RESPONSE TO AN AGRO-FOOD SYSTEM IN CRISIS: THE G.A.S. PHENOMENON IN ITALY}

\author{
Flavio Sacco dos Anjos and \\ Nadia Velleda Caldas
}

Keywords: Alternatives agro food networks; Solidarity Economy; Political Comsumption; Critical Comsumption; Italy.

This article is inserted in the global debate about the dynamics of alternative agro-food networks. The main objective of this study consists in analyzing the constitution and operation of the Gruppi di Acquisto Solidale (G.A.S), currently considered the most important experience of political consumption of Italy. This study is based on in-depth interviews held with various actors connected to this initiative (producers, consumers, technicians etc.). The focus is to demonstrate that it is not only a unique modality of buying and selling agro-food products, but of a broader movement that challenges the production, distribution and agro-food consumption mainstream in the whole planet. The contribution of this study is to stimulate the reflection about the importance of these processes as objects of sociological observation, among the effects caused by agro-food scandals in the actuality.

\section{UNE RÉPONSE SOLIDE À UN RÉGIME AGROALIMENTAIRE EN CRISE : LE PHÉNOMÈNE GAS EN ITALIE}

\author{
Flavio Sacco dos Anjos et \\ Nadia Velleda Caldas
}

Mots-clés: Réseaux agroalimentaires alternatifs; Économie solidaire; Consommation politique; Consommation critique; Italie.

Cet article s'insère dans le débat global sur la dynamique des réseaux agroalimentaires alternatifs. L'objectif central de ce travail consiste à analyser la constitution et le fonctionnement des Gruppi di Acquisto Solidale, considéré de nos jours comme l'expérience de consommation politique la plus importante d'Italie. L'étude est basée sur des entretiens approfondis menés avec plusieurs acteurs liés à cette initiative (producteurs, consommateurs, techniciens, etc.), dont l'objectif est de montrer qu'il ne s'agit pas uniquement d'une modalité singulière d'achat et de vente de produits agroalimentaires, mais d'un mouvement plus large qui défie le courant dominant (mainstream) de la production, de la distribution et de la consommation agro-alimentaire en cours dans l'ensemble de la planète. La contribution du travail consiste à provoquer une réflexion autour de l'importance de ces processus en tant qu'objet d'observation sociologique, dans le cadre des effets découlant des scandales agroalimentaires. 